\title{
Editorial
}

\section{Basel Committee on Banking Supervision: Compliance and the compliance function in banks}

Bank regulation and supervision provides an external framework of rights and obligations in which banks operate so that they can undertake regulated activities in the financial market place. This framework, inter alia, attempts to use formal mechanisms of internal self-regulation within the bank to ensure compliance. Therefore, bank regulation and supcrvision provides the context for undertaking regulated business so that risks can be sufficiently managed to ensure that competitiveness and profitability do not adversely threaten to destabilise the firm, depositors' and investors' interests, or market confidence. The caveat is the fact that bank regulation and supervision does not try and eliminate the likelihood of loss, failure or fraud. In this respect, bank supervisors have, over a considerable period of time, placed more cmphasis on effective corporate governance in banks to reduce the likelihood of risks becoming unmanageable. This editorial outlines the Basel Committee on Banking Supervision's new high-level principles on the issue of compliance in banks.

The Basel Committee on Banking Supervision in October 2003 published a consultation paper entitled 'The compliance function'. This paper has now been superseded by its amended version entitled 'Compliance and the compliance function', published in April 2005, which sets down a number of high-level principles to ensure effective compliance. ${ }^{2}$ This set of principles supersedes the consultation paper published in October 2003 and sets the compliance function within a much broader context than the previous paper. This paper builds on its previous work on, inter alia, internal controls, corporate governance, internal audit, customer due diligence and operational risk. These papers disseminate best practice to try and strengthen aspects of corporate governance in banks. The compliance function is a central part of a bank's system of accountability and is required to ensure that the bank adheres to financial regulation, in its widest sense, set by respective regulatory authorities wherever it undertakes its business. In this respect, it is not simply sufficient to ensure the rules exist within a bank but show that they are applied in substance to manage compliance risk. Moreover, compliance with legal and regulatory rules is a responsibility that transcends the whole organisation and is not a function simply located in a single department to administer.

The central theme of the compliance function is not simply to act as an internal 'watchdog' but to work with the business units to minimise the likelihood of compliance risks occurring. This is to make sure that the bank does not, inter alia, breach the laws, rules and standards governing its business activities, which could result in a variety of regulatory sanctions.

The 2005 set of principles pertaining to compliance moves away from simply devising principles to strength the role of the compliance function in banks - it 
takes a broader look at how compliance is ensured in such institutions. It indicates that compliance needs to be a part of the culture of the bank and the responsibility of all within it, in particular the board of directors and senior management on whom the authority is placed to set the appropriate climate against non-compliance within the organisation. The idea of compliance per se is interpreted to refer to 'standards of market conduct, managing conflicts of interest, treating customers fairly, and ensuring suitability of customer advice'. ${ }^{3}$ In addition to these the 2005 principles also refers to laws concerning the prevention of money laundering and terrorist finance. The 2005 principles set the context for a compliance function by referring to the idea of compliance risk rather than simply referring to a compliance function. The Basel Committee defines compliance risk in the following manner:

'[T]he risk of legal or regulatory sanctions, material financial loss, or loss to reputation a bank may suffer as a result of its failure to comply with laws, regulations, rules, related self-regulatory organisation standards, and codes of conduct applicable to its banking activitics. $^{4}$

This definition removes the suggestion that compliance is simply a responsibility of a single department although it does indicate that the existence of a compliance function does ensure such risks are managed more effectively if one exists in a bank. The 2003 consultation paper referred to a compliance function as 'an independent function that identifies, assesses, advises on, monitors and reports on the bank's compliance risk'. This would seem to suggest that the single compliance department would have sole responsibility for dealing with compliance risks, which is not normally the case, as a legal department, for instance, would be equally involved with dealing with such issues at some stage. Indeed in some large banks there is a designated risk committee or operational risk committee devoted to aspects of compliance risk, which work alongside the compliance function.

The Basel Paper outlines ten principles for an effective compliance policy. The board of directors are conferred the responsibility to approve, oversee and assess a bank's compliance policy, and compliance risks. ${ }^{6}$ It is then the responsibility of senior management to manage effectively a bank's compliance risk on a day-to-day basis. ${ }^{7}$ This is further elaborated on by referring to their responsibility to ensure that the compliance policy is observed and periodically reviewed within the bank. ${ }^{8}$ The Basel principles also confer on senior management the responsibility of establishing an effective compliance function within the bank in conformity with the bank's compliance policy. ${ }^{9}$

The Basel Paper then provides several principles that govern specifically the compliance function. It refers to the importance of its compliance function to be independent. ${ }^{10}$ In order to ensure their independence, the compliance function needs to be given the appropriate status in the bank by ensuring the compliance policy addresses inter alia its role and responsibility, its relationship with the internal audit function, the right to seek information and carry out investigations. The bank needs to have in place a senior manager to head and coordinate compliance within the organisation. Conflicts of interests need to be monitored so that they do not undermine the integrity of the compliance function. The compliance function needs to have access to information and personnel of a bank so that it can carry out its responsibilities. The bank needs to ensure the compliance function has the appropriate level of resources to carry out its responsibilities. ${ }^{11}$

The Basel principles provide that the 
compliance function needs to assist senior management in effectively managing compliance risks that may arise in a bank. ${ }^{12}$ In order to undertake this task it needs to cooperate with other departments involved in dealing with compliance risks. The compliance function is said to need to assist senior management in a number of ways: to provide advice, guidance and education, identify, measure, assess and report compliance risks.

The Basel Committee also provides the work of the compliance function needs to be periodically reviewed by the internal audit function. ${ }^{13}$ The compliance risks do cmanate from other jurisdictions so it is important for a bank with overseas activitics that the risks are appropriately captured by a compliance function whether it is located in the home or host market. ${ }^{14}$ Finally, the compliance function which is outsourced needs to be subject to appropriate oversight by the bank. Indeed it should also be accessible to appropriate levels of supervision. ${ }^{15}$

The high-level principles certainly build on other aspects of the Basel Committee's work in the area of internal governance. The principles place the obligation for an effective compliance risk approach firmly on the banks. It will be for the bank supervisors to assess whether they are effectively complying with its compliance policy. The bank supervisor cannot be too accommodating with cases of non-compliance because it could undermine the integrity of the banking system.

\section{References}

(1) Basel Committee on Banking Supervision, Consultative Document: The Compliance Function in Banks, October 2003. This was outlined in Singh, D. (2003) 'Editorial, Basel Committee on Banking Supervision: The Compliance Function in Banks', Journal of International Banking Regulation, Vol. 5, No. 2, p. 110.

(2) Basel Committee on Banking Supervision (2005) 'Compliance and the Compliance Function in Banks', April.

(3) Ibid., p. 7.

(4) Ibid., p. 7.

(5) Ref. 1 above, p. 3.

(6) Ibid., Principle 1.

(7) Ibid., Principle 2.

(8) Ibid., Principle 3.

(9) Ibid., Principlc 4.

(10) Ibid., Principle 5.

(11) Ibid., Principle 6.

(12) Ibid., Principle 7.

(13) Ibid., Principle 8.

(14) Ibid., Principle 9.

(15) Ibid., Principle 10.

Dr Dalvinder Singh

Senior Lecturer in Law Oxford Brookes University IALS Editor 